\title{
Using stated preference methods to assess environmental impacts of forest biomass power plants in Portugal
}

\author{
Anabela Botelho ${ }^{1} \cdot$ Lina Lourenço-Gomes ${ }^{2} \cdot$ Lígia Pinto $^{3}$. \\ Sara Sousa $^{4} \cdot$ Marieta Valente $^{3}$
}

Received: 1 October 2015/Accepted: 14 April 2016/Published online: 23 April 2016

(C) Springer Science+Business Media Dordrecht 2016

\begin{abstract}
As a renewable energy source, the use of forest biomass for electricity generation is advantageous in comparison with fossil fuels; however, the activity of forest biomass power plants causes adverse impacts, affecting particularly neighbouring communities. The main objective of this study is to estimate the effects of the activity of forest biomass power plants on the welfare of two groups of stakeholders, namely local residents and the general population. To this end, we apply two stated preference methods: contingent valuation and discrete choice experiments, respectively. The former method was applied to estimate the minimum compensation residents of neighbouring communities of two forest biomass power plants in Portugal would be willing to accept. The latter method was applied among the general population to estimate their willingness to pay to avoid specific environmental impacts. The results show that the presence of the selected facilities affects individuals' well-being. On the other hand, in the discrete choice experiments conducted among the general population all impacts considered were valued, in particular odour and fauna and flora impacts. The results of this study stress the importance of performing an equity analysis of the welfare effects on different groups of stakeholders from the installation of forest biomass power plants, as their effects on welfare are location and impact specific. Policy makers should take into account the views of all stakeholders either directly or indirectly involved when deciding crucial issues regarding the sitting of new forest biomass power plants, in order to achieve an efficient and equitable outcome.
\end{abstract}

Lígia Pinto

pintol@eeg.uminho.pt

Marieta Valente

mvalente@eeg.uminho.pt

1 DEGEI and GOVCOPP, University of Aveiro, Aveiro, Portugal

2 CETRAD and DESG, University of Trás-os-Montes and Alto Douro, Vila Real, Portugal

3 EEG and NIMA, University of Minho, Braga, Portugal

4 ISCAC, Polytechnic Institute of Coimbra, Coimbra, Portugal 
Keywords Forest biomass - Stated preference methods - Contingent valuation - Discrete choice experiments $\cdot$ Environmental impacts $\cdot$ Public attitudes

\section{Introduction}

Climate change, $\mathrm{CO}_{2}$ emissions and security of energy supply are major national concerns nowadays. Moreover, most countries, including Portugal, face a situation of significant external energy dependency. These issues represent strong motivations for the development of renewable energy sources (RES), which, in addition to using domestic resources, impose less important environmental impacts than fossil sources: RES generate fewer greenhouse gases (GHG) emissions, namely $\mathrm{CO}_{2}$, no radioactive wastes and lower levels of other pollutants. However, RES are not completely "environmentally benign" and may, in fact, be responsible for causing adverse impacts on the environment and people's wellbeing (OECD/IEA 1998). Differing either in kind or in intensity between the different technologies, the impacts due to the operation of the different renewables facilities are more noticeable locally and immediately in comparison with most non-renewable energy sources. As such, these negative impacts should not be neglected when it comes to addressing efficiency and equity issues during the decision-making process. In this study, we focus on a particular RES, namely forest biomass (FB) energy for electricity production to explore the perspectives of the two groups of stakeholders involved, namely local residents, who suffer the negative impacts of the operation of the plants, and the general population, who ultimately benefit. We apply economic non-market valuation methods to elicit the economic value of those impacts from the perspective of the two groups of stakeholders in relation to FB plants located in Portugal.

Forest biomass energy is a RES with clear benefits in particular in what concerns the potential to reduce GHG emissions (Mabee and Saddler 2007; UN 2007) and can therefore play a key role for the fulfilment of the European and Portuguese goals with respect to climate change, as it can contribute for the supply of energy both in electricity generation and in heating or cooling processes with low greenhouse house gas intensity. Furthermore, bioenergy projects can foster local development in rural areas where they are based and contribute to the reduction in external energy dependency and increase in energy security. Overall, there is evidence supporting the expansion and promotion of electricity generated from biomass (Enersilva 2007; Evans et al. 2010; Carneiro and Ferreira 2012; CAM 2013). In the particular case of Portugal, there is high potential for using this type of fuel (Ferreira et al. 2009), especially because of the considerable forest area of 3.15 million hectares, representing $35.4 \%$ of the national territory (ICNF 2013). Moreover, the use of FB as a fuel for energy purposes reduces the risk of forest fires, a major concern in Portugal, particularly in the summer season.

Notwithstanding the many advantages of using biomass for electricity production, the activity of forest biomass power plants (FBPP) is not harmless, affecting individuals' wellbeing, particularly those who reside in the neighbouring areas of the power plants. Miranda and Hale (2001) undertook a full social cost analysis in Sweden and concluded that removal of forest biomass residue affects soil, water, biota and future soil productivity; in particular, it reduces the quantity of available nutrients and increases soil carbon content which is linked to soil fertility (Lamers et al. 2013; Armolaitis et al. 2013 found similar results) and its capacity to retain water. However, these results are not unanimous, and Lamers et al. (2013) found no long-term effect on forest productivity. Related to forest productivity is the loss of biodiversity of fauna and flora, which again is not consensual (Siitonen 2001). Jonsell (2007) 
using the landscape history as focus of analysis found that the impacts depend on the specific forest species under analysis. Regarding social acceptance and perception of the environmental impacts, Upreti and Horst (2004) concluded that there is considerable opposition to forest biomass in the UK. Opposition to FB stems from concerns about: emission of water vapour, unpleasant odour, vibration and noise, emission of light at night, increased traffic and related noise and air pollution (Schlamadinger and Marland 2001), visual effects from height of the chimneys, decreased property values, decrease in tourist activities, negative effects on cultural heritage and archaeological sites, among others. In addition, one common concern is the effect on landscape; however, while Dockerty et al. (2012) found no significant effect, Miranda and Hale (2001) found significant results although they also conclude that most environmental effects and their value are site specific and uncertain. Upreti and Horst (2004) found that familiarity was an important determinant of the social attitude towards FBPP.

When deciding whether and where to implement a FB project, all costs and benefits of that type of RES and of the particular location of the FBPP need to be identified and accounted for. Therefore, the costs imposed on local communities by the plants should be included. As stated in Owens (2004) in discussing the sitting of large-scale facilities "the problem of finding sites is frequently construed as meeting some national need whilst ensuring justice for local communities who bear the brunt of environmental hazards and costs" (p. 101). Using as an application FBPP in Portugal, we aim to provide one framework to estimate the (economic) value associated with the environmental impacts. We apply stated preference methods, which are methods used to elicit economic value of goods and services for which there is no functioning market, so-called non-market goods. One approach is to take the perspective of local residents and estimate such value through the compensation required by them to offset the costs experienced. In this case, we apply the contingent valuation (CV) method. Another approach is to consider the beneficiaries of such projects, which are the general population and elicit their willingness to pay local residents to compensate them for the damage sustained. To implement this approach, we design a discrete choice experiment (DCE).

Overall, this study allows us to estimate the welfare compensation measures taking the perspective of the two groups of stakeholders. The results show that the presence of FBPP has significant welfare impacts on habitants of surrounding communities. In addition, the general population reveals having clear preferences regarding specific environmental impacts of FBPP and being willing to pay non-trivial and attribute-specific monetary amounts to have electricity produced using FBPP so as to avoid each environmental impact. Furthermore, these estimations can be used as the basis for efficiency considerations, in terms of how they compare, and for equity considerations given the asymmetry of the costs and benefits. Finally, the comparison of those measures hints at the feasibility of a compensation transfer between the two groups.

The remainder of this paper is organized as follows. Section 2 provides an overview of the main methodological issues, the valuation methods explained, the survey design described and a brief description of the case studies presented. Then, Sect. 3 presents and discusses the results. Finally, in Sect. 4 the main conclusions of this paper are presented.

\section{Methodology}

\subsection{Stated preference methods}

Determining the economic value of the environmental impacts caused by the generation of electricity in FBPP is far from being simple, since there are no markets for the 
environmental goods and services impacted and, therefore, prices are not available. Nevertheless, the inexistence of prices for environmental impacts does not imply that they have no value. These types of resources are called non-market goods, and their value may be estimated through either revealed preferences or stated preferences methods. While in the former method, the goods' value is inferred based on the observation of consumers' behaviour, stated preference methods ask consumers what they would be willing to pay or accept for a change in an environmental amenity (Adamowicz et al. 1994). Hence, direct methods do not require individuals to make any behavioural change, they only ask individuals to attach an economic value to some non-marketed good or service. Stated preference methods have advantages over revealed preferences methods. First, stated preference methods can be used to value any environmental good or service, even at levels of quality that currently do not exist. Second, they often provide the only viable alternative for measuring non-use values. In particular, non-use values may be the most important social values in some policy contexts, such as endangered species and wilderness preservation. Furthermore, these methods may be used to elicit values in cases in which the environmental quality change involves a large number of attributes (Adamowicz et al. 1994; Bateman et al. 2002; Mendesohn and Olmstead 2009). In spite of some criticism attached to stated preference methods, their competent application can add information to benefit-cost analysis (e.g. Haab et al. 2013). We present in Sects. 2.2 and 2.3 the stated preference methods used in this study.

\subsection{Contingent valuation}

The CV method is a direct survey approach to estimating consumer preferences. Using an appropriately designed questionnaire, a hypothetical (or contingent) market for the good in question is described. This contingent market defines the good itself, the institutional context in which it would be provided, and the way it would be financed. Respondents are then asked to express their maximum willingness to pay (WTP) or minimum willingness to accept (WTA) compensation for a hypothetical change in the level of provision of the good (Mitchell and Carson 1989; Hanley et al. 2001; Atkinson and Mourato 2008).

In this study, we designed a CV survey with the aim of estimating the minimum monetary amount respondents would be willing to accept as compensation for the burdens caused by the presence of a FBPP in the proximity of their residence. Most contingent valuation applications elicit respondents' willingness to pay welfare measure, following the recommendations of the NOAA panel (Arrow et al. 1993). The argument advanced by the panel is that given the hypothetical nature of the payment involved it is easier to analyse the consistency of willingness to pay responses than of willingness to accept, because the first are conditioned on the ability to pay, while the latter have no natural reference point. However, in this application, the willingness to accept format was chosen as local populations are already experiencing the presence of the power plants and its possible detrimental impacts; thus, the correct measure of welfare change is the income equivalent variation, in this case a willingness to accept compensation question. Moreover, in a previous study Botelho et al. (2013) showed, in a similar application, that respondents' answers to willingness to accept questions were not unreasonable if compared with respondents' characteristics, like income.

Following Whitehead (2006), each questionnaire was composed of four parts. After an introductory part with general questions on renewable energy sources, part 2 presents specific questions on the production of electricity through forest biomass, of which we discuss here, for its relevance, the valuation question. Due to the fact that we had no prior 
information on the distribution of respondents' valuation for choosing the thresholds for a discrete choice format, this question was formulated as an open question. The payment vehicle chosen was a return in the electricity bill. The question was formulated as follows:

Taking into account your income and your usual expenses, answer the following question: What is the minimum amount that you would be willing to receive as compensation for the inconvenience that the presence of the forest biomass power plant causes you? The amount would be credited to your monthly electricity bill.

You would be willing to receive Euros per month.

Part 3 contains some additional questions on respondents' preferences and opinions on different energy sources, renewable and non-renewable. Finally, part 4 includes some questions on individuals' socio, economic and demographic characteristics (e.g. gender, educational level, family situation and income). The questionnaire was subject to an interactive test and review process using pilot studies (Botelho et al. 2014).

\subsection{Discrete choice experiments}

The DCE method is based on the notion that value is derived from the specific attributes of a good, in accordance with Lancaster (1966)'s characteristics theory of value. This surveybased approach has the advantage that respondents are simply required to choose their preferred option out of a series of set of alternatives that differ by the attributes/levels present. In each choice task, respondents trade off changes in attribute levels against the associated cost (Hanley et al. 1998, 2001; Bateman et al. 2002; Pearce et al. 2001, 2006). The application of DCE in the present context aims at eliciting respondents' preferences regarding the environmental effects of FBPP. The identification of respondents' preferences is relevant since, and as the severity of the environmental impacts considered depends on the location, it is important to known the hierarchy of the impacts on respondents' preferences and the value they attribute to each in order to choose the location that minimizes overall impacts.

DCE questionnaires are structured in four parts. First, the degree of respondents * familiarity with renewable energy sources was assessed in an introductory section. Part 2 comprises the choice experiment section, in which individuals were presented with six choice sets, each consisting of a choice between two alternative ways of producing electricity through forest biomass, differing on the levels of specific attributes. The selection of attributes was based on a mixed approach method using quantitative and qualitative techniques explained in Botelho et al. (2014). Through a D-efficient design (NGene

Table 1 Choice set example

\begin{tabular}{llc}
\hline & Form A & Form B \\
\hline Significant impact on the landscape & Yes & No \\
Significant impact on the fauna/flora & Yes & No \\
Produces smell affecting population & Yes & No \\
Increase in the monthly electricity bill $€$ & $\square$ & 8 \\
Your choice & $\square$ & $\square$ \\
\hline
\end{tabular}

Consider the choice between form A of electricity generation through biomass and form B of electricity generation also through biomass. Tick your preferred option 
software), the attributes' levels were combined into alternatives paired in six choice sets. Table 1 presents one of the six choice sets given to respondents for illustration: Then, respondents were presented with two more parts with questions on respondents' preferences and opinions on different energy sources (part 3) and to gather information on the individuals' socio, economic and demographic characteristics (part 4).

\subsection{The sample}

The sample selection process for the two populations was different. For the case of residents in the vicinity of FB power plants, we first selected the specific plants, and then went to the villages in several trips, recruited respondents in public places, and conducted the questionnaires, through personal interviews, in private places. The invitation to participate in the survey had no information regarding the objective of the survey; thus, no selfselection bias with respect to the subject is expected. In some villages, we had the collaboration of the local church to do the announcement and public presentation of the interviewing team. The sites selected were Mortágua and Constância. During the first and third weeks of June 2014, a total of 48 questionnaires were collected among the residents, namely 20 questionnaires in Constância and 28 in Mortágua. Despite the small size of the sample, we are confident, based on the selection process, that our respondents constitute a fair (and feasible) representation of local residents. In fact, the sample is composed of the residents present at public places at the time of the interviews that were willing to participate.

The Mortágua power plant is located in the parish of Mortágua, municipality of Mortágua, district of Viseu, in centre of Portugal (Figs. 1, 2). Created with the aim of reducing the risk of forest fires, this plant, operating since 1999, is fuelled exclusively by forest residues (natural gas is only used as a regulatory and start-up fuel). According to Patrão (2011), Mortágua was considered a good location to implement the power plant, because the region has about $27 \%$ of the total Portuguese forested areas and produces around 480,000 tons/year of dry forest residues. Another important reason to choose this location was the high number of wood industries in the region, namely sawmills, which produce wood residues such as bark. The Mortágua power plant, with an installed capacity of 10

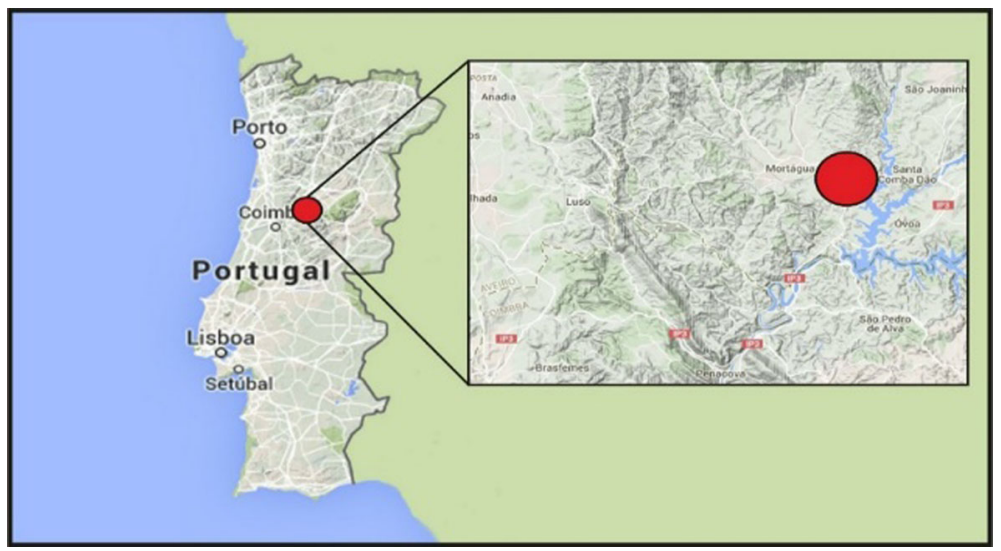

Fig. 1 Location of Mortágua Source: Authors' elaboration 


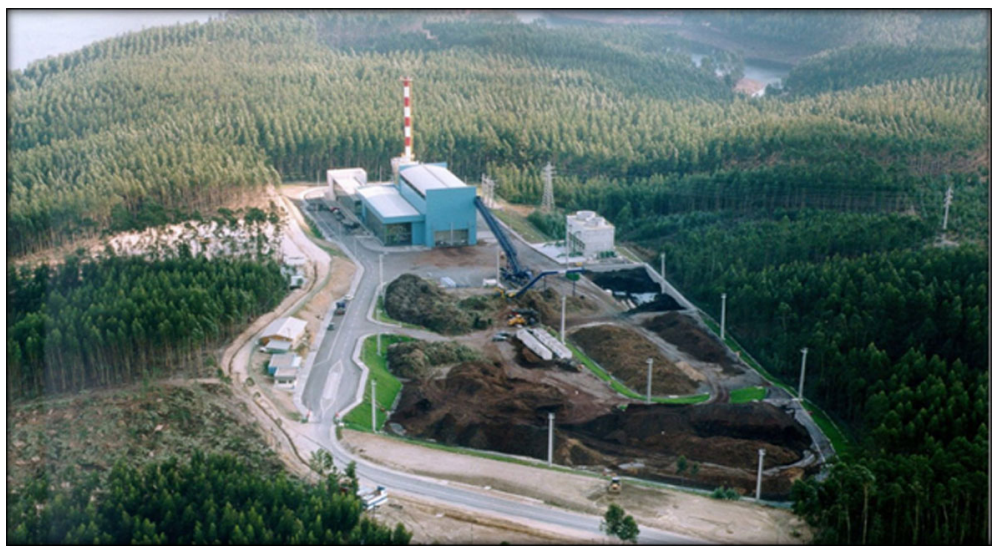

Fig. 2 FBPP panoramic image of Mortágua FBPP Source: EDP

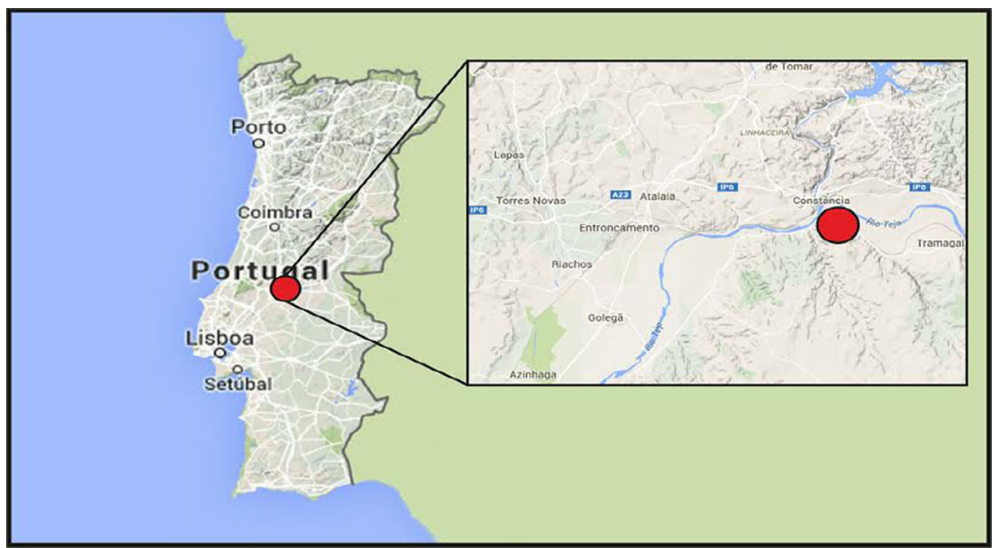

Fig. 3 Location of Constância Source: Authors' elaboration

MVA, produces $60 \mathrm{GWh}$ of electricity and consumes 110 thousand tons of forest residues (pine and eucalyptus bark) annually (DGEG 2007; Patrão 2011).

The Constância power plant, installed in the industrial perimeter of the Caima pulp mill, is located in the parish and municipality of Constância, district of Santarém, in centre of Portugal (Figs. 3, 4). Operating since 2009, the Constância power plant is also fuelled exclusively by forest residues (natural gas is only used as a regulatory and start-up fuel) and is determinant both for the energy valorization of the region forest resources and for reducing the risk of forest fires. The Constância power plant, with an installed capacity of 14.5 MVA, produces $80 \mathrm{GWh}$ of electricity and consumes 160 thousand tons of forest residues annually (Patrão 2011).

The sample for the DCE questionnaire was selected randomly from the population of all the districts in mainland Portugal, tentatively ensuring some representativeness by age, education and gender. The administration of the questionnaires was done through a professional surveying firm. The questionnaires were filled in during a personal interview. 


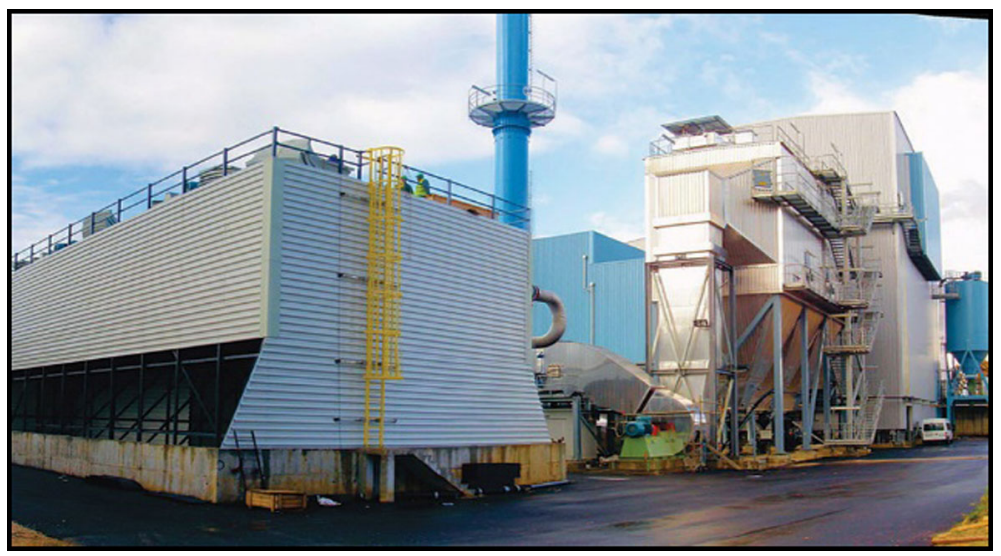

Fig. 4 FBPP panoramic image of Constância FBPP Source: EDP

Data were collected during the first semester of 2014. In total, 250 questionnaires were conducted among the general population residing in mainland Portugal. The sample was randomly selected from the general adult population.

\section{Results}

\subsection{Local residents}

Local residents' sample is characterized by low levels of education, about half of the respondents have only attained primary education level, $35 \%$ are retired, mean age is 55 years old, mean monthly per capita household income is approximately 450 Euros and on average respondents pay around 60 Euros for electricity per month. Regarding the respondents' relationship with FBPP, for most of them (76\%) the plant is visible from their homes or in their daily commute between home and work. Moreover, about half of the respondents feel entitled to some compensation amount, with an average of 33.48 Euros per month.

The data collected on respondents' willingness to accept can be modelled as a two-stage process, whereby respondents first decide whether they should receive compensation and then, if so, how much should that compensation be (in integer positive amounts). As such, it is appropriate to fit a two-part or hurdle model to take this two-stage process into account, allowing for different determinants of the first hurdle (i.e. expressing entitlement to a compensation) and then of the compensation amount (conditional on having expressed entitlement in the first stage). This type of specification allows for the zeros in the first stage to be explained differently from the compensation values (Cameron and Trivedi 2009, p. 569). A second issue that needs to be accounted for in the empirical specification concerns the high frequency of zeros associated with CV studies, which calls for a zeroinflated model (Cameron and Trivedi 2005, pp. 680-681). Therefore, we applied the zeroinflated negative binomial model using Stata (Cameron and Trivedi 2009).

The reduced number of observations imposes some constraints on the econometric model specification, namely regarding the number of estimated coefficients; thus, as 
Table 2 Zero-inflated negative binomial model

\begin{tabular}{|c|c|c|c|c|}
\hline & Coefficient & Robust standard error & Marginal effects & Standard error \\
\hline \multicolumn{5}{|l|}{ WTA yes/no } \\
\hline Mortágua & $2.0017 * * *$ & $(0.7048)$ & & \\
\hline Constant & -1.2546 & $(0.5739)$ & & \\
\hline \multicolumn{5}{|l|}{ WTA amount } \\
\hline Income pc & $-0.0005^{* * *} *$ & $(0.0001)$ & $-0.0076 * * *$ & $(-0.0026)$ \\
\hline Annoyance & $0.3349 * * *$ & $(0.0821)$ & $48,154 * * *$ & $(1.5540)$ \\
\hline Self-interest & $-0.3297 * *$ & $(0.1713)$ & $-4.8304 *$ & $(2.7338)$ \\
\hline Mortágua & 0.1379 & $(0.2728)$ & $-10.0245^{*}$ & $(5.8298)$ \\
\hline Constant & $2.8567 * * *$ & $(0.3654)$ & & \\
\hline $\operatorname{Ln}(a l p h a)$ & $-1.8661 * * *$ & $(0.2196)$ & & \\
\hline \multicolumn{5}{|c|}{$N: 46($ zero $=23) ;$ Wald $\chi^{2}(4) 42.22 * * *$} \\
\hline
\end{tabular}

* Significance level of $10 \%$; ** significance level of $5 \%$; *** significance level of $1 \%$

determinants of the decision to receive compensation we include a dummy variable identifying the FBPP (the dummy included is for the Mortágua plant and Constância is the omitted category). To explain the amount demanded we include in addition to the location, monthly per capita family income, the level of annoyance caused by the FBPP (on a 1-5 increasing scale), whether the respondent worked or had any friend or family working in the FBPP (which we term self-interest). Table 2 reports the results.

Table 2 shows that location significantly affects the probability of a respondent feeling entitled to compensation, with residents close to Mortágua power plant being more likely to demand compensation. With respect to the willingness to accept amount, it is positively affected by the degree of annoyance experienced and negatively affected by the per capita income. Moreover, respondents having self-interest in the power plant either because they work/worked in the plant or have family or friends working/worked there, demand lower amounts of compensation on average, as expected. In particular, for each 100 Euros increase in respondents' per capita income, the amount of compensation demanded decreases 7.60 euros, holding the other variables constant; respondents who have selfinterest demand on average 4.83 euros less than those that have no self-interest; and those annoyed demand on average 4.82 Euros more than residents who do not feel annoyed.

Based on the regression model, we predict that the amount of compensation would be on average 14.38 Euros per month, being 27.33 Euros in Constância and 7.89 Euros in Mortágua, which matches the dimension of the FBPP, as Constância is the FBPP with higher installed capacity. Moreover, the Constância power plant is sited very close to residences and public places like cafes and is therefore more visible to the residents of the local community. Thus, we conclude that the presence of the FBPP affects local residents' well-being and has a non-negligible impact on local welfare levels. Moreover, the impacts differ by income level of respondents and by how they relate to the FBPP in terms of annoyance felt and self-interest of respondents.

\subsection{Non-residents}

General population sample respondents are on average 49 years old and have a household per capita income of 605.50 Euros. Also, $44 \%$ of the respondents are male, and $34 \%$ are 
retired. With regard to qualifications, $30 \%$ hold a graduate degree. The vast majority of respondents are familiar with production of electricity through renewable energies except for geothermal energy which is unknown to most respondents, and they overwhelmingly consider them environmentally friendly. In relation to respondents' self-interest in renewable energies, $12 \%$ report knowing someone who has worked with some renewable energy technologies. One important indication of the importance attributed to renewable energy is the interest that respondents have in the type of energy source used in the production of the electricity they consume: $37 \%$ of respondents consider it very important. The monthly average electricity bill of respondents is approximately 69 Euros, and half of respondents say they observe the electricity bill with detail. Regarding choices involved in the DCE, $18 \%$ of respondents say they considered all attributes when choosing between forms of producing electricity in each choice set.

The DCE, routed in the Random Utility theory, assumes that the utility that respondent $n$ derives from the choice of two alternatives (parametrized as 0 and 1 ) is, respectively, $U_{0}=\beta_{0}^{\prime} \mathbf{x}+\varepsilon_{0}$ and $U_{1}=\beta_{1}^{\prime} \mathbf{x}+\varepsilon_{1}$, in which $\mathbf{x}$ represents all observed covariates (e.g. alternatives attributes, respondents' characteristics) and $\varepsilon_{0}$ and $\varepsilon_{1}$ are the unobserved or random components of the individual's utility. The respondent will choose alternative 1 if $U_{1}>U_{0}$, or $\varepsilon_{0}-\varepsilon_{1}<\beta_{0}^{\prime} \mathbf{x}-\beta_{1}^{\prime} \mathbf{x}$. A probability model is estimated (since the error terms are unknown), where $P_{1}=\left[\varepsilon_{0}-\varepsilon_{1}<\beta_{0}{ }^{\prime} \mathbf{x}-\beta_{1}{ }^{\prime} \mathbf{x}\right]$. Assuming that the random parts of the utility functions $\left(\varepsilon=\varepsilon_{0}-\varepsilon_{1}\right)$ are distributed as independent extreme value, the binary logit model follows, based on the logistic distribution:

$$
F=\frac{\exp \left(\beta^{\prime} x_{n}\right)}{1+\exp \left(\beta^{\prime} x_{n}\right)}=\Lambda\left(\beta^{\prime} x_{n}\right) .
$$

When multiple observations are obtained from the same respondent (which is the case in the DCE framework, as several choice situations are presented to respondents), panel data models are appropriate. A possible extension of the binary logit model to panel data is the random parameters logit (RPL) model (see, e.g. Revelt and Train 1998; McFadden and Train 2000; Hensher and Greene 2003), in which the parameters are randomly distributed across individuals. The specific parameter vector is defined by

$$
\beta_{n}=\beta+\sigma v_{n},
$$

where $\beta$ is the population mean and $v_{n}$ represents the individual specific heterogeneity, $\sigma$ is the standard deviation of the distribution of $\beta_{n}$ around $\beta$ (Greene 2012). Due to the presence of random terms that can take distributional forms such as normal, triangular lognormal or uniform, the unconditional RPL probability has no closed form (as in a logit model) being approximated by a simulation procedure. The parameters are estimated through maximizing the simulated log likelihood.

In the present application, the choice between the two generic alternatives of forest biomass energy by respondent $n$ in choice set $t$ is analysed through the specification of a RPL model taking into account the heterogeneity of random preferences and the panel nature of the dataset. Assuming a linear additive utility function, the utility that respondent $n$ derives from the choice of the form $i$ (of production of electricity using biomass) in choice set $t$ is written as:

$$
U_{\text {nit }}=\beta_{0}+\beta_{n}^{\prime} X_{\text {nit }}+\alpha P_{\text {nit }}+\varepsilon_{\text {nit }}, \quad i=1,2
$$


Table 3 Random parameters logit

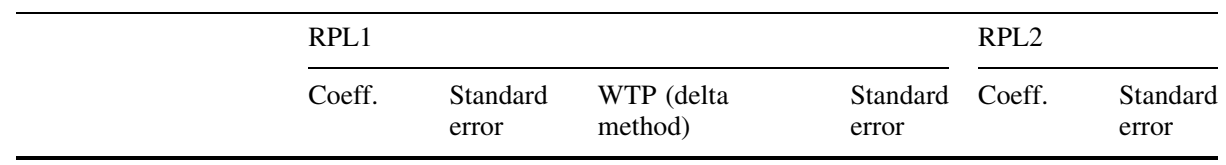

Fixed parameters

Price

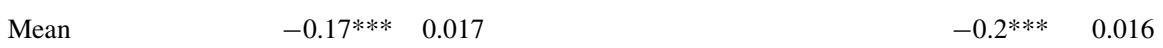

Random parameters

Landscape

$\begin{array}{lllllll}\text { Mean } & -1.03 * * * & 0.09 & 6.04 * * * & 0.6 & -0.42 * * * & 0.16 \\ \text { SD } & 1.47 * * * & 0.09 & & & 1.06 * * * & 0.08 \\ \text { Fauna/flora } & & & & & \end{array}$

$\begin{array}{lllllll}\text { Mean } & -2.25 * * * & 0.1 & 13.2 * * * & 1.1 & -3.3 * * * & 0.19 \\ \text { SD } & 3.03 * * * & 0.15 & & & 2.5 * * * & 0.12 \\ \text { Odour } & & & & & & \\ \text { Mean } & -2.05 * * * & 0.1 & 12.03 * * * & 0.94 & -0.42 * * & 0.17 \\ \text { SD } & 3.04 * * * & 0.15 & & & 2.6 * * * & 0.12 \\ \text { ASC } & & & & & \\ \text { Mean } & 3.98^{* * * *} & 0.23 & & 3.16^{* * *} & 0.25 \\ \text { SD } & 0.75^{* * *} & 0.06 & & 0.31 * * * & 0.06\end{array}$

Interactions (heterogeneity in the means of random parameters)

asc $\times$ EDU
asc $\times$ AGE
asc $\times$ KnowBio
Landscape $\times$ EDU
Landscape $\times A G E$
Landscape $\times$ Know
Fauna $\times$ EDU
Fauna $\times$ AGE
Fauna $\times$ KnowBio
Odour $\times$ EDU
Odour $\times$ AGE
Odour $\times$ KnowBio

LL0

$\mathrm{LL}_{\text {Model }}$

Pseudo- $R^{2}$

$\mathrm{AIC} / \mathrm{N}$

Chi-squared

$N(n)$

Variables: $\mathrm{AGE}=1$ if age $>49$ years $(0$ if not $)$; KnowBio $=1$ if the respondent is aware of biomass energy ( 0 if not); EDU $=1$ if years of schooling $>9$ ( 0 if not)

* Significance level of $10 \%$; ** significance level of $5 \%$; *** significance level of $1 \%$ 
where $X_{\text {nit }}=$ attributes of the alternatives (impacts on landscape, impacts on fauna/flora, odour); $P_{\text {nit }}=$ Price attribute (increase in the monthly electricity bill); $\beta_{0}=$ Alternative Specific Constant (ASC),

$$
\beta_{n}^{\prime}=\left(b^{\prime}+s^{\prime} \eta_{n}\right)
$$

$b^{\prime}=$ population mean; $s^{\prime} \eta_{n}=$ independent random deviates representing the deviation from the mean; $\eta=$ randomness in the coefficients, assumed to be random and normally distributed, ${ }^{1}$ implying that $\beta \sim N\left(b, s^{2}\right)$.

Table 3 reports the estimation results of the RPL model (NLOGIT ${ }^{\circledR}$ Econometric $^{-}$ Software, Inc., version 5.0) with simulated maximum likelihood using Halton draws with 500 replications.

As reported in Table 3 (RPL1), the means of the random parameters (all the environmental impacts) are statistically significant at explaining the choice of a specific way of producing electricity through biomass energy. The standard deviations are statistically significant and large detecting the presence of unobserved heterogeneity over the sample. The non-random parameter (price) is also statistically significant and negative, suggesting that higher prices produce greater disutility in choosing an alternative.

Predicted average WTP is reported in the last column of the RPL1. The hierarchy of the WTP measures mimics that of the effect of the attributes on respondents' welfare. On average, respondents are willing to pay about 13 Euros monthly to avoid the effects on fauna/flora and $12 €$ to avoid the odour impact. Their WTP to avoid effects on landscape is much smaller: 6 Euros per month, approximately. In sum, respondents distinguish between attributes, revealing statistically significant impacts of each attribute on their utility level. In addition, predicted average WTP is similar for two attributes but significantly different for one of the attributes considered.

The RPL2 introduces some interactions terms to capture sources of observed heterogeneity. There are differences in the marginal utilities held for the three attributes which can be explained by differences in individual characteristics (educational level, age and knowledge of biomass energy). Relatively to the landscape impacts, there is evidence of heterogeneity by level of education.

\subsection{Comparing results}

The use of the contingent valuation and discrete choice experiments approaches in this application allowed the analysis of the welfare effects of two sets of stakeholders: local residents potentially negatively affected by the presence of the FBPP and the population in general that may potentially benefit for example from lower $\mathrm{CO}_{2}$ emissions (in comparison with fossil fuels) and thus experience welfare benefits. Given that our study collected a sample of local residents and a national sample, there are noteworthy differences in the population characteristics and as a consequence in the samples collected. The most relevant difference of the two samples regards income, age and education, with local residents being older, less educated and with less income.

\footnotetext{
${ }_{1}$ As the direction of the preferences is not clear (the parameters may have positive or negative values), the impact attributes are specified as normally distributed. As a conventional procedure, the price attribute will be specified as a fixed or non-random parameter.
} 
Through the $\mathrm{CV}$ method, we were able to predict that the compensation amount demanded by local residents would be on average 14.38 Euros per month. On the other hand, the application of the DCE method among the general population allowed us to conclude that, on average, respondents are willing to pay between $[6 € ; 13 €]$ depending on the impact considered.

The residents to be compensated are those living close to the installations, while those willing to pay are ultimately the entire population, so the compensation amount would be well below the maximum potential compensation the general population would be willing to pay. Therefore, these often neglected environmental impacts as experienced and valued by local residents can be offset by a monetary compensation, which, pending equity considerations, would mean that concerning the focus of this study the use of FBPP is potentially welfare improving. More broadly, there are undeniable benefits of using RES in electricity production, in particular forest biomass, so it is safe to conclude that these benefits more than compensate the additional costs we valued on this study (namely, the environmental impacts experienced by the general population as valued by the two groups of stakeholders).

\section{Conclusions}

Portuguese energy policy and the introduction of targets concerning the share of renewable energy used within Europe have increased the demand for forest biomass electricity generation. FBPP are generally seen as environment-friendly, much like renewable energy sources in general, but they are not environmentally impact free. In deciding between energy sources to produce electricity, policy decision-makers should analyse the "equity implications" of the projects. A proper equity analysis requires identifying all stakeholders and an evaluation of the welfare change for each group following the implementation of a FBPP. Through the use of the CV method, we were able to identify the adverse impacts caused by the activity of two FBPP on local residents and compute the monetary amount they demand as compensation for the negative impacts that the plants impose on them. The results show that the amount demanded is sensitive to socio-demographic characteristics of the respondents and also on the degree of annoyance felt by them, in addition to being site specific. Thus, the results show that choice of site and possibly size of the plant appear to be significant determinants of respondents' WTA, which translates into the amount of compensation for the damages caused by the plant.

On the other hand, the application of the DCE method among the general population allowed us to value each environmental impact caused by the operation of the FBPP and conclude that unpleasant odour and impacts on fauna and flora are the effects more valued by respondents.

Based on our results, it is clear that public decision-makers need to realize that there is an equity problem, which should be minimized when deciding the construction and location of new FBPP. By applying stated preference methods, we can estimate the value of the environmental impacts of these projects and include it for efficiency and equity analysis. Also, from our results there appears to be scope for a compensation transfer between the two groups of stakeholders. With this study, we expect to contribute to a more complete decision-making process for future forest biomass power development.

Acknowledgments The authors gratefully acknowledge the financial support from FCT Fundação para a Ciência e Tecnologia with Grant Number PTDC/EGE-ECO/122402/2010. 


\section{References}

Adamowicz, W., Louviere, J., \& Williams, M. (1994). Combining revealed and stated preference methods for valuing environmental amenities. Journal of Environmental Economics and Management, 26, 271-292.

Armolaitis, K., Varnagiryte-Kabasinskiene, I., Stupak, I., Kukkola, M., Miksys, V., \& Wojcik, J. (2013). Carbon and nutrients of Scots pine stands on sandy soils in Lithuania in relation to bioenergy sustainability. Biomass and Bioenergy, 54, 250-259.

Arrow, K., Solow, R., Portney, P., Leamer, E., Radner, R., \& Schuman, H. (1993). Report of the NOAA Panel on Contingent Valuation. Federal Register, 58(10), 4601-4614.

Atkinson, G., \& Mourato, S. (2008). Environmental cost-benefit analysis. Annual Review of Environment and Resources, 33, 317-344.

Bateman, I., Carson, R., Day, B., Hanemann, M., Hanley, N., Hett, T., et al. (2002). Economic valuation with stated preference techniques: A manual. Edwar Elgar: Cheltenham.

Botelho, A., Lourenço-Gomes, L., Pinto, L.M.C., \& Sousa, S. (2014), How to design reliable discrete choice surveys: The use of qualitative research methods. In 2 nd international conference on project evaluation-ICOPEV 2014, organized by CGIT-Research Centre for Industrial and Technology Management, School of Engineering of University of Minho, 26-27 June 2014, Guimarães.

Botelho, A., Pinto, L. M. C., \& Sousa, P. (2013). Valuing wind farms' environmental impacts by geographical distance: A contingent valuation study in Portugal. Working Paper NIMA 52, Braga, Universidade do Minho, 2013.

CAM—Comissão de Agricultura e Mar (2013). Relatório: Grupo de Trabalho da Biomassa, Junho de 2013. Edição: Assembleia da República.

Cameron, A. C., \& Trivedi, P. K. (2005). Microeconometrics: Methods and applications. Cambridge: Cambridge University Press.

Cameron, A. C., \& Trivedi, P. K. (2009). Microeconometrics using Stata. College Station, TX: Stata Press.

Carneiro, P., \& Ferreira, P. (2012). The economic, environmental and strategic value of biomass. Renewable Energy, 44, 17-22.

DGEG-Direcção Geral de Energia e Geologia (2007). Energias Renováveis em Portugal. Renewable Energy in Portugal.

Dockerty, T., Appleton, K., \& Lovett, A. (2012). Public opinion on energy crops in the landscape: Considerations for the expansion of renewable energy from biomass. Journal of Environmental Planning and Management, 55(9), 1134-1158.

Enersilva (2007). Enersilva-Promoção do uso da Biomassa Florestal para fins energéticos no sudoeste da Europa, 2004-2007. Projecto Enersilva.

Evans, A., Strezov, V., \& Evans, T. J. (2010). Sustainability considerations for electricity generation from biomass. Renewable and Sustainable Energy Reviews, 14(5), 1419-1427.

Ferreira, S., Moreira, N. A., \& Monteiro, E. (2009). Bioenergy overview for Portugal. Biomass and Bioenergy, 33(11), 1567-1576.

Greene, W. (2012). NLOGIT, version 5.0. Reference guide. Plainview, NY: Econometric Software, Inc.

Haab, T. C., Interis, M. G., Petrolia, D. R., \& Whitehead, J. C. (2013). From hopeless to curious? Thoughts on Hausman's "Dubious to Hopeless" critique of contingent valuation. Applied Economic Perspectives and Policy, 35(4), 593-612.

Hanley, N., Wright, R. E., \& Adamowicz, V. (1998). Using choice experiments to value the environment: Design issues, current experience and future prospects. Environmental \& Resource Economics, 11(3-4), 413-428.

Hanley, N., Wright, R. E., \& Mourato, S. (2001). Choice modelling approaches: A superior alternative for environmental valuation. Journal of Economic Surveys, 15(3), 435-462.

Hensher, D. A., \& Greene, W. H. (2003). The mixed logit model: The state of practice. Transportation, 30(2), 133-176.

ICNF-Instituto da Conservação da Natureza e das Florestas (2013). $6^{\circ}$ Inventário Florestal Nacional: Áreas dos usos do solo e das espécies florestais de Portugal continental (resultados provisórios).

Jonsell, M. (2007). Effects on biodiversity of forest fuel extraction, governed by processes working on a large scale. Biomass and Bioenergy, 31, 726-732.

Lamers, P., Thiffault, E., Paré, D., \& Junginger, M. (2013). Feedstock specific environmental risk levels related to biomass extraction for energy boreal and temperate forests. Biomass and Bioenergy, 55, 212-226.

Lancaster, K. (1966). A new approach to consumer theory. Journal of Political Economy, 84, $132-157$.

Mabee, W. E., \& Saddler, J. N. (2007). Forests and energy in OECD countries, Food and Agriculture Organization of the United Nations-Forests and Energy working paper 1. 
McFadden, D., \& Train, K. (2000). Mixed MNL models for discrete response. Journal of Applied Econometrics, 15, 447-470.

Mendesohn, R., \& Olmstead, S. (2009). The economic valuation of environmental amenities and disamenities: Methods and applications. Annual Review of Environment and Resources, 34, 325-347.

Miranda, M., \& Hale, B. (2001). Protecting the forest from the trees: The social costs of energy production in Sweden. Energy, 26, 869-889.

Mitchell, R. C., \& Carson, R. T. (1989). Using surveys to value public goods: The contingent valuation method. Resources for the Future: Washington DC.

OECD/IEA (1998). Benign energy? The environmental implications of renewables. Organisation for Economic Co-operation and Development and International Energy Agency.

Owens, S. (2004). Siting, sustainable development and social priorities. Journal of Risk Research, 7(2), $101-114$.

Patrão, G. (2011). The Portuguese energy strategy and the role of biomass. In Workshop BIOGAIR: Biomass on the Portuguese energy sector. University of Aveiro, Aveiro, 13th of May, 2011.

Pearce, D., Atkinson, G., \& Mourato, S. (2006). Cost-benefit analysis and the environment: Recent developments. Paris: OECD.

Pearce, D., Mourato, S., \& Wright, R. (2001). Environmental cost-benefit analysis: Recent developments. Paris: OECD.

Revelt, D., \& Train, K. (1998). Mixed logit with repeated choices: Households' choices of appliance efficiency level. Review of Economics and Statistics, 80(4), 647-657.

Schlamadinger, B., \& Marland, G. (2001). The role of bioenergy and related land use in global net $\mathrm{CO}_{2}$ emissions. In Woody biomass as an energy source-challenges in Europe, EFI Proceedings no 39, pp. 21-27.

Siitonen, J. (2001). Forest management, Coarse Woody Debris and Saproxylic Organisms: Fennoscandian Boreal forests as an example. Ecological Bulletins, 49, 11-41.

UN (2007). Sustainable bioenergy: A framework for decision makers. United Nations-Energy.

Upreti, B., \& Horst, D. (2004). National renewable energy policy and local opposition in the UK: The failed development of a biomass electricity plant. Biomass and Bioenergy, 26, 61-69.

Whitehead, J. C. (2006). A Practitioner's Primer on the Contingent Valuation Method. In A. Alberini \& J. R. Kahn (Eds.), Handbook on contingent valuation (pp. 66-91). Cheltenham: Edward Elgar. 